\title{
Filosofía analítica de la religión
}

\section{ENRIQUE ROMERALES}

La filosofía de la religion es hoy una de las ramas de la filosofía más representativas del ámbito anglosajón. Actualmente goza de una situación similar a la que poseían en los años cincuenta o sesenta disciplinas como la filosofia del lenguaje o de la ciencia, esto es, cuenta con casi medio siglo de tradición y está en plena efervescencia. Si bien podemos remontar el origen de nuestra disciplina hasta Jenófanes, en el mundo analítico la constitución de una comunidad nutrida de filósofos de la religión aparece hacia los años cincuenta. ${ }^{1}$ Hemos trazado recientemente un amplio panorama temático de la filosofia analítica de la religión en nuestros días, ${ }^{2}$ por lo que aquí haremos un breve recorrido histórico para referirnos finalmente al estado actual y a la situación en España.

La filosofía de la religión adquiere notoriedad en el ámbito académico como disciplina y cuenta con un nutrido número de componentes a partir de los años cincuenta en Gran Bretaña y, en seguida, en los EEUU, Australia o Nueva Zelanda. En un principio se trata, en muchos casos, de lógicos y filósofos del lenguaje o de la ciencia (John Wisdom, Arthur N. Prior, Anthony Flew, John Mackie, Norman Malcolm, William Alston, Richard Braithwaite) que aplican sus teorias a la religión y teología. Aunque ha pasado el apogeo del positivismo lógico, en los cincuenta es aún la corriente filosófica dominante y, en bastantes casos, son discípulos suyos quienes aplican tales ideas a la religión de un modo sumamente crítico. Naturalmente tales desarrollos no surgieron de la nada, sino que obras precedentes tocaban marginalmente las cuestiones teológicas y religiosas en el pensamiento anglosajón, entre ellas el Diario filosófico, las referencias finales del Tractatus o las de las Observaciones, por parte de Wittgenstein; el ¿Por qué no soy cristiano? de Russell, ${ }^{3}$ o el capítulo 6 de Lenguaje, verdad y lógica, de Ayer.

De este modo, hacia los años cincuenta las cuestiones de lenguaje y significado dominaban la filosofía de la religión como el resto de la filosofía. El problema principal era si el veredicto condenatorio de la teología que había pronunciado el empirismo lógico era justo o, por contra, la teología tenía su propia lógica - lo que era más acorde con las ideas del análisis lingüistico procedentes del segundo Wittgenstcin-o, en último caso, como se pretendería más adelante, podía salvarse la religión liberándola del excesivo peso de la leología. Así en $1955^{4}$ surge la primera gran obra colectiva, los New Essays in Philosophical Theology, en que muchos y diversos filósofos discuten el significado de las aserciones teológicas y su valor. En esta "época de las parábolas» se discute si los enunciados teológicos tienen o no sígnificado y si, de tenerlo, tienen alguna verosimilitud. Podemos agrupar del siguiente modo a los filósofos según su veredicto: a) quienes aceptan las ideas del empirismo lógico (o, en su caso, del falsacionismo) y su aplicación a los temas religiosos, para concluir que la teología o bien no expresa ningún conocimiento o bien es radicalmente falsa, y la religión (la cristiana al menos) una actividad irracional e inaceptable (Mackie, Flew, Martin, Smart, Nielsen, Edwards y un largo etcétera). $b$ ) Quienes acep- 
tando que el empirismo lógico arruina la teología, creen que la religión puede salvarse independizándola de aquella o que, al menos, tiene cierto valor como actividad humana - afectiva, emocional, expresiva o algo similar- (Holland, McPherson, Hare, MacIntyre, Braithwaite). c) Quienes aceptando eI desafio empirista pretenden "rellenar de contenido" fáctico a la teología sin pretender que sea ningún tipo de ciencia sino, más bien, reivindicando sus asertos metafísicos (Hick, Mitchell, Crombie). ${ }^{5}$ En seguida apareceran las que, d) no aceptan las ideas positivistas, y menos su aplicación a cuestiones de religión sino que, guiados por el segundo Wittgenstein, piensan que la religión es un juego de lenguaje que "se juegan, sin duda porque expresa una peculiar forma de vida, y -en varios autores- se añadirá que tal juego es independiente por completo de creencias y por tanto toda teología -filosófica o revelada - superflua (Malcolm, Hudson, Phillips, Winch, etc.). Y como grupo añadido, e) quienes desde la teologia aprovechan en parte las ideas del segundo Wittgenstein, y en parte las del tercer grupo, para aclarar el uso del lenguaje teológico cristiano que justifica su significado y significancia (Ramsey, ${ }^{6}$ Macquarrie, Mananzan, Prozesky).

En efecto, en 1957 un grupo de filósofos metafísicos de Oxford publica la obra colectiva Faith and Logic ${ }^{7}$ que justamente pretende dar cuenta de la lógica de la fe frente a las criticas empiristas, aunque aceptando buena parte de sus presupuestos. Y ya en los sesenta el análisis lógico y conceptual abre paso al planteamiento de genuinas cuestiones teológicas. Así en 1964 el Princeton Theological Seminary convoca un seminario en cuyas actas, en las que participan unos cincuenta filósofos, aparecen tópicos como la experiencia religio- sa o la existencia de Dios bajo el hilo conductor de la racionalidad de la creencia religiosa. ${ }^{8}$

Ya en plenos sesenta la ampliación de temas corre pareja a la incorporación de nuevos filósofos, y con cllo a la proliferación de simposios y seminarios, que hacia los setenta producirá la proliferación de antologías, selecciones de textos e introducciones a la disciplina. ${ }^{9}$ Así, por cjemplo, Alvin Plantinga - uno de los autores más originales y seguramente quien más ha revitalizado la filosofía de la religión- publica en $1967 \mathrm{God}$ and Other Minds, ${ }^{10}$ libro de difícil clasificación, en el que se sostiene que, aun con la ausencia de pruebas o evidencias, la racionalidad del teísmo no es inferior a la de la creencia on las otras mentes. $O$ los dos capítulos finales de su influyente The Nature of Necessity, ${ }_{r}^{11}$ que tocan decisivamente dos de los problemas clásicos del teísmo que vuelven a estar de actualidad: el argumento ontológico y el problema del mal. Respecto del primero, las importantes aportaciones - mutuamente contradictoriasde Findlay y Prior en los cincuenta, ${ }^{12}$ el primero presentando una concluyente refutación ontológica, y el segundo una posible vía de aceptación de la existencia necesaria, dieron paso en los sesenta a las obras de Hartshorne y Malcolm ${ }^{13}$ que, de modo muy similar, reivindicaban a san Anselmo como formulador de un segundo argumento ontológico (inerme a los ataques tanto de Hume como de Kant, y a la par del empirismo lógico) que venía a afirmar, no que la existencia es una perfección, sino que la existencia necesaria lo es. Plantinga, tras rechazar primero este «segundo argumento" construye una nueva versión, válida según él, y que ha hecho que en los setenta y ochenta las versiones del argumento ontológico y sus sucesivas refutaciones proliferen de un modo que ha llegado a ser alarmante. ${ }^{14}$ 
Respecto del problema del mal, la estrategia de Plantinga consistió en desmontar el ataque del siguiente modo. Mackie habla afirmado en "Evil and Omnipotence" ${ }^{15}$ que la existencia del mal era logicamente incompatible con la existencia de un Dios creador sumamente bondadoso y omnipotente. Se afirma que el mal moral es el precio de la libertad pero, arguye Mackie, si es posible que los hombres actúen bien en cualquier ocasión dada, entonces es posible que actúen bien en toda ocasión, pero, dada la omnipotencia divina, Dios podía - y debía- haber creado criaturas libres que siempre actuaran bien. No haberlo hecho refuta su bondad o su misma existencia. Contra esto Plantinga expuso la Free Will Defence, ${ }^{16}$ que sostiene, grosso modo, que annque hay mundos posibles en los que los hombres actúan libremente siempre bién (pues cabe tal posibilidad lógica), la omnipotencia divina no puede actualizar uno de tales mundos pues ello equivaldría a superponer la acción divina sobre la libertad humana - quedando esta última anulada-. Esto justificaría plenamente el mal moral; en cuanto al mal físico Plantinga alegó que, dado que Dios puede tener razones que se nos escapan para permitir dicho mal, su existencia, por sí misma, no es incompatible con la existencia de Dios; a lo sumo, la existencia de tal mal hace improbable la existencia de Dios. Pero para defender el argtmento probabilistico a partir del mal ${ }^{17}$ hace falta sa. ber de cuál de las distintas concepciones de la probabilidad estamos hablando (logica, estadística, etc.) y contar con una concepción unitaria de dicho tipo de probabilidad, lo que no sucede. $Y$, en segundo lugar, aunque la probabilidad de la existencia de Dios frente al mal fuera baja, podría elevarse sustancialmente al tener en cuenta otros hechos como p.e. la experiencia reli- giosa-. Además, como no hay modo de cuantificar el mal, no hay modo de asignar un valor determinado a la probabilidad de la existencia de Dios frente al mal. En suma, la estrategia de Plantinga frente al problema del mal, luego seguida por otros muchos, consiste en retraer más y más el argumento epicúreo hacia sus fundamentos lógicos, de modo que cualquier conclusión ateológica quede indefinidamente bloqueada. La otra linea principal de argumentación acerca de este problema está constituida por la denominada "soul making theodicy" cuyo mayor representante es John Hick, quien en su Evil and the God of Love, de 1966, ${ }^{18}$ ataca el problema de frente intentando construir una teodicea irenista consistente en argumentar que, para que podamos disfrutar de un estado futuro de bienaventuranza, seguramente es necesario que primero pasemos por las penalidades de una vida como esta, a fin de poder alcanzar un estado de conocimiento y voluntad en el que libremente actuemos siempre bien. En suma, sin ser un tema lan candente como el argumento ontológico, el problema del mal nunca ha dejado de estar presente, y cuenta con importantes contribuciones en los setenta y ochenta. ${ }^{19}$

Pero volviendo al inicio de los setenta, otro de los temas candentes en esta epoca es el desarrollo de una "filosofía del lenguaje religioson, e incluso de una entera filosofía de la religión, basada en el Wittgenstein de las Investigaciones filosóficas y de Sobre la certeza, ${ }^{20} \mathrm{en}$ vez de en el empirismo lógico. Así en 1975 un congreso en Lancaster reúne a una veintena de filosofos alrededor del tópico: cuál es la posición de Wittgenstein sobre la religión, y qué valor tienen sus ideas para la filosofía de la religión. 21 En realidad, el enfoque wittgensteiniano se remonta bastante atrás, probablemente a la obra colectiva "fun- 
dacionals editada por Dewi Z. Phillips, Religion and Understanding. ${ }^{22}$ Desde luego, no todos los wittgensteinianos entienden por igual la religión. Hay desde quienes defienden una religiosidad agnóstica porque la religión contiene expresiones, no creencias, hasta quienes afirman que hay creencias religiosas, si bien carecen de fundamento racional, lo cual no es grave porque todo sistema de afirmaciones - ciencia incluida - carece de una justificación última. La postura estándar vendría a consistir en lo siguiente: no hay un lenguaje ni una lógica. Al contrario, hay muchos e inconmensurables juegos de lenguaje y cada uno tiene su propia lógica. Si queremos una instancia última de apelación que decida qué juegos hay que practicar, no la hay. A eso podemos llamarlo carencia de fundamentación, de justificación racional última -algo intrínseco a todo sistema humano-. Qué es una prueba y qué una refutación, qué es sin sentido y qué tiene sentido, qué vale y qué no, se decide siempre dentro de un juego de lenguaje, dentro de cada sistema. Cada juego de lenguaje representa una forma de vida. La decisión de a qué juegos de lenguaje jugar, de en qué formas de vida participar, ni es ni puede ser una decisión racional basada en evidencias o argumentos. Normalmente viene dictada por la comunidad a la que pertenecemos, por tradición y educación. Una sociedad diferente tendrá una cultura diferente, unas prácticas y formas de vida diferentes y dificilmente entenderemos sus juegos de lenguaje -porque un juego de lenguaje sólo se comprende desde dentro-. Lo importante, entonces, es que haya una comunidad viva y numerosa que practique determinada forma de vida y su correspondiente juego de lenguaje. Esto ocurre en el caso de las religiones, particularmente de la cristiana. No hay necesidad de más justificación (en cuanto a la justificación de las prácticas y actitudes inherentes a una forma de vida, ésta es siempre interna). Algunos, como Winch, van más allá, para afirmar que la religión no tiene nada que ver con las creencias, con las hipótesis, que los enunciados teológicos y sus problemas son puros malentendidos de los filósofos. La religión es un ámbito de sentimientos y emociones, de expresiones, un modo de ver la vida, una determinada actitud hacia el mundo. Si no hay creencias que defender, si no hay ningún contenido asertivo, la argumentación racional está por completo fuera de lugar. El que usted o yo participemos o no en determinada forma de vida religiosa es filosóficamente irrelevante.

Las críticas a tal posición no se hicieron esperar. ${ }^{23}$ Las fundamentales son: a) que muchas de las actitudes y prácticas religiosas presuponen logicamente determinadas creencias (como que hay un Dios, o una vida ultraterrena). Por ejemplo, no tiene sentido rezar para pedir algo o agradecer algo, a menos que creamos que hay alguien que nos escucha y es capaz de darnos lo pedido o cs (al menos en parte) responsable de lo acaecido. b) Que tales creencias son de hecho esenciales para muchas religiones. c) Que tales creencias presentan problemas y que la argumentación es relevante para defender tales creencias frente a las críticas. $d$ ) Que los juegos de lenguaje no son mundos aislados sino interconectados, y que se pueden comprender también desde fuera. e) Precisamente por esto se puede entrar en o salir de un juego de lenguaje. f) Que frente al relativismo sociocultural en que nos deja Wittgenstein, en realidad hay unos procedimientos racionales argumentativos comunes a todas las culturas $\mathrm{y}$, desde luego, a todos los juegos de lenguaje que comportan 
creencias -filosofia, ciencia y religión incluidos-, etc. Estas justificadas críticas han hecho que la influencia de tal corriente haya disminuido progresivamente hasta su casi extinción ya en los noventa.

Frente a estas críticas, algunos como Cupitt ${ }^{24}$ han reaccionado diciendo que no se trata tanto de describir cómo es la religión ni cómo actúan los creyentes, cuanto de prescribir cómo ha y habrá de ser la religión si quiere seguir cumpliendo sus exigencias morales y estar a la altura de los tiempos; unos tiempos en los que las creencias teológicas son tan anacrónicas como superfluas. Pero es cuando menos dudoso que cualquiera de las religiones bíblicas pueda seguir cumpliendo su papel social y moral si se desprende por completo de sus afirmaciones teológicas.

Siguiendo con los años setenta, al inicio de la década se desarrolló otra línea de investigación bien delimitada (que, por supuesto, contaba con antecedentes), aunque de alcance más restringido. Se trata de la problemática de la relación entre la moral y la religión, cuyo abanico de doctrinas va desde quienes afirman que la existencia de un Dios que ordena inapelablemente impediría la libertad y autonomía necesarias para que surja la moral, hasta quienes afirman que sólo la obediencia a un Dios con poder absoluto podría justificar lógicamente el cumplimiento del deber, y con ello la ética; pasando por quienes piensan que la autonomía moral humana y la omnipotencia y exigencias divinas son compatibles. Así en 1971 James Rachels publicó un artícu$10^{25}$ en el que intentaba demostrar la inexistencia de Dios parafraseando en cierto modo al célebre "Can God's Existence Be Disproved" de Findlay. Según Rachels, necesariamente, quienquiera que sea Dios, ha de ser un ser digno de culto. Pero un ser digno de culto re- quiere obediencia incondicional, y ningún ser moralmente autónomo puede obedecer incondicionalmente a otro. Pero, seguramente, los hombres somos moralmente autónomos (en el sentido kantiano). Luego no es posible que haya un ser digno de culto. Rachels pretende mostrar la incompatibilidad entre la autonomía moral humana y la existencia de un legislador absoluto divino. Philip Quinn ${ }^{26}$ intentó escapar del dilema mostrando que es posible la coexistencia de Dios con seres moralmente autónomos en al menos dos casos: el mundo posible en el que Dios no dispone ningún mandato, y aquel en el que sólo dispone aquellos mandatos a los que un ser moralmente autónomo puede asentir. El argumento de Rachels, aunque lógicamente válido, sería inaceptable por tener una premisa falsa. Más adelante, ${ }^{27}$ Quinn ha desarrollado toda una teoría del mandato divino compatible con la autonomía moral $y$, de paso, ha aclarado muchos aspectos de la aplicación de la lógica deóntica al problema de la relación entre moral y religión, especialmente la lógica del requerimiento. Sin embargo, Quinn ha sido acusado de presuponer la bondad absoluta de Dios, lo que sería inconsistente con una teoria del mandato divino. ${ }^{28}$ Pero, más recientemente, ha afirmado que, puesto que Dios está por encima de la moral, la obligación de obedecerle no puede ser moral sino más bien religiosa. ${ }^{29}$ Tampoco ha sido el único en pretender que la existencia de un legislador supremo no suprime la moralidad y libertad humanas: Nelson Pike ha presentado una teoría cuasi ockamista de la relación moral-religión; Richard Swinburne, una escotista según la cual Dios podría modificar las leyes morales contingentes que ha dispuesto, pero no las necesarias; Robert Adams, una semiagustiniana en la que, aunque creemos que Dios es sumamen- 
te bueno y le obedecemos por ello, es lógicamente posible que Dios ordene males de por sí, con lo que nuestra noción de lo éticamente incorrecto se vendria abajo, ya que «incorrecto" significa "prohibido por Dios" ${ }^{30}$ Por último, para Geach, Dios no sólo es compatible sino necesario para la moral, porque el único modo de justificar desde un punto de vista lógico la no realización de un acto es que esté absolutamente prohibido (o sea, por Dios). La cuestion "¿por qué he de obedecer a Dios?" sería para Geach insensata. ${ }^{31}$ El tema sigue sobre el tapete y últimamente se han realizado intentos de contestar a Rachels sin aceptar las tesis de Quinn. ${ }^{32}$

Para acabar con los años setenta mencionaré dos temas centrales de lo que se denomina Philosophical Theology, esto es, la teología natural actualizada, ${ }^{33}$ como núcleo de la filosofía de la religión. ${ }^{34}$ Me refiero a la naturaleza divina y a las "pruebas" de la existencia de Dios. Se trata de dos temas algo preteridos en la filosofía de la religión hasta hace poco -especialmente cl úlimo-, debido probablemente a tres razones: que los filósofos teístas estaban demasiado ocupados en la actitud defensiva de contestar adecuadamente las críticas efectuadas por sus colegas agnósticos y ateos; que la historia de la filosofía cuenta ya con una abundante apologética sobre tal tema; y que no es fácil construir nuevos argumentos que eludan las severas críticas que tal tradición sufrió (sobre todo las aparentemente decisivas de Hume y Kant).

Tal vez sea Richard Swinburne quien más concienzudamente haya llevado a cabo la tarea de (re)construir una noción filosóficamente aceptable de Dios y recoger todos los argumentos y evidencias posibles en favor del teismo. ${ }^{35}$ Partiendo de que el lenguaje teológico ha de tomarse -al menos en parte-. literalmente, ha tratado de explicitar el significado de los principales atributos divinos: el ser un Espíritu Omnipresente, Creador, Omnipotente, Omnisciente, Perfectamente bondadoso, Eterno e Inmutable. Sobre cada uno de estos tópi$\cos$ hay abundante bibliografía $y$, en varios casos, un autor se ha especializado en un determinado atributo divino. ${ }^{36}$ Aquí no podemos extendemos sobre el particular pero, a título de ejemplo mencionaremos el tema de la omnisciencia. Tradicionalmente se ha pensado que la omnisciencia divina implicaba el conocimiento de los futuros contingentes, lo que chocaba con la también inexcusable libertad humana. Si Dios sabe que voy a hacer $x$ no es posible que haga no $x$. ¿Como entonces voy a ser libre? Segín Swinburne, a $x$ es omnisciente» significa " $x$ conoce todas las proposiciones verdaderas". Pero si los enunciados sobre futuros contingentes carecen de valor de verdad, entonces no hay proposiciones verdaderas al respecto que un ser omnisciente deba conocer. Como quiera que la libertad humana implica que las acciones futuras humanas son todas contingentes, Dios no puede saber (porque así lo ha dispuesto) cuáles van a ser nuestras acciones, sin que ello vaya on menoscabo de su omnisciencia. Aquí vemos cómo la teología filosófica al desembarazarse de un dogma teológico (que Dios sabe lo que va a pasar incluso respecto las acciones de los seres libres) puede resolver limpiamente un inveterado problema filosófico.

Desde luego, los filósofos analíticos actuales han puesto en duda la interpretación $e$ incluso la realidad (y la conveniencia) de muchos de los atributos tradicionalmente predicados de Dios. Por ejemplo, la inmutabilidad divina puede interpretarse de muchas maneras. En su sentido fuerte implica la impasibilidad, y en el más fuerte la 
inmutabilidad de las propiedades relacionales. Pero hay un acuerdo generalizado (Hartshome, Geach, Swinburne) en que la inmutabilidad divina sólo afecta a sus propiedades esenciales no relacionales, esto es, que Dios puede cambiar en el sentido de, por ejemplo, empezar a amar o dejar de amar a alguna criatura, perdonar, o conocer sus acciones presentes. La cuestión de la inmutabilidad está muy ligada a la eternidad divina que también ha sido interpretada de diversos modos: estar en todo tiempo (Tillich), sempitemidad (Kneale, Wolterstorff), o atemporalidad en el sentido clásico (Helm). En definitiva se trata de interpretar de la forma filosóficamente más satisfactoria cada atributo divino, $y$ después acomodarlos entre si para formar un concepto unitario coherente. El problema de fondo en el tema de los atributos divinos es compaginar un concepto filosóficamente depurado (sea el ser perfecto, el ser en sí, lo allende el ser y la ousia, la Realidad ulitma o cualquiera de las dcmás fórmulas tradicionales) con las exigencias religiosas que Dios ha de cumplir. Dicho en román paladino: ¿cómo puede el Ipsum esse subsistens ser un «padre», una "Persona", ser "vivo", conocernos, amarnos, perdonamos o condenarnos? Hay, obviamente, toda una amplia corricnte muy crítica dedicada a mostrar que nada de esto es posible. ${ }^{37}$

En cuanto a las "pruebas" de la existencia de Dios, hoy ya no se trata obviamente de demostrar, sino de poner en la balanza cuantos más argumentos $y$ evidencias posibles en favor del teísmo, para que estas se vayan acumulando hasta pesar más que los argumentos en contra. ${ }^{38}$ Respecto de los argumentos cosmológico y teleológico lo más destacado es la versión inductiva de Swinburne. Aplicando el teorema de Bayes (que viene a decir que si, dado el conocimiento global de fondo, la ver- dad de una hipótesis aumenta la probabilidad de un hecho, entonces la ocurrencia del hecho aumenta la probabilidad previa de la hipótesis), Swinburne afirma que si la existencia de Dios aumenta la probabilidad de la existencia del mundo, y sobre todo la probabilidad de la existencia de un alto grado de orden en el universo (dado que Dios seguramente tiene razones para crear y, caso de hacerlo, sin duda deseara crear algo ordenado que pueda cumplir sus fines), entonces la existencia de un mundo con un orden tan elevado como el presente aumenta notablemente la probabilidad antecedente de la existencia de Dios. ${ }^{39}$ ¿Hasta qué punto? Swinburne trata de cuantificar las probabilidades para mostrar que, si bien el argumento teleológico por sí solo no hace que la probabilidad de la existencia de Dios sea mayor que la de su inexistencia, sí puede tener peso suficiente para - junto con los derriás argumentos- inclinar la balanza de las evidencias en favor del teismo. Sin embargo, Mackie, O'Hear y Hick han negado que el aumento de probabilidad sea realmente significativo. ${ }^{40}$

Finalmente, en la década de los ochenta acontece una auténtica explosión de publicaciones en nuestra materia. El tema que se lleva la palma es el de la problemática entre razón y fe. Dicho tema ha sido una preocupación constante en la filosofia analítica de la religión; de hecho, si una cuestión es el hilo conductor de la disciplina en el presente siglo es esta: "¿es atin racional y razonable creer en Dios?". Pero a principios de esta década aparece la apologética de la creencia básica promovida por un grupo de filósofos americanos capitaneados por Plantinga. Su obra "fundacional" es el colectivo Faith and Rationality, ${ }^{41}$ La idea es, grosso modo, la siguiente. Hay dos tipos de creencias, las que se derivan de otras deductiva o 
inductivamente, y las que no son derivadas. Llamemos básicas a estas últimas. Pues bien, la doctrina xoficial", el fundacionalismo, ha sostenido que sólo pueden ser básicas aquellas proposiciones que sean autoevidentes y/o evidentes a los sentidos y/o incorregibles. Esto es, la evidencia debe ser su justificación última. Sin embargo, muchas de nuestras creencias más ilustres (que existen otras mentes, que mi memoria es generalmente fiable) son básicas aunque no cumplen ninguno de tales requisitos. Es cierto que a menudo lo que en la estructura noética de una persona se toma como básico, en la de otra cuenta como derivado. Pero en cualquier caso, dichas creencias básicas no se basan en evidencias ni en razones, por contra, ellas son el fundamento sobre el cual basar las evidencias y los razonamientos. Pero como tales creencias son necesarias es racionalmente aceptable profesarlas. Pues bien, para muchos creyentes, la existencia de Dios es una creencia básica en este mismo sentido. Por ello la evidencia y la argumentación en su favor $\rightarrow$ no así las evidencias en contra- son irrelevantes, ya que las creencias básicas no se sostienen sobre la base de evidencias, sino de modo inmediato si se dan las circunstancias apropiadas. Intentando aclarar cuáles son tales circunstancias, William Alston $^{42}$ ha explicado que la experiencia religiosa ordinaria del creyente (Plantinga habla del "sentido de la presencia divina») es el locus adecuado. En realidad Plantinga ha advertido que aunque cualquier creencia puede ser básica en una estructura noética si así lo decide su portador, no todas las creencias son propiamente básicas sino sólo las que cumplan determinados requisitos (p.e., que no haya fuerte evidencia en contra, o razones adicionales para suponer que la creencia es falsa). Pero Plantinga no ofrece un criterio de basicalidad propia ya que según él lo más que puede haber son ejemplos de creencias propiamente básicas a partir de los cuales operar inductivamente. El problema es que "no hay razón para asumir, por adelantado, que todo el mundo estará de acuerdo en los ejemplos", y se descuelga diciendo que ula comunidad cristiana [sólo] es responsable de su conjunto de ejemplos».43

Las numerosas criticas se han referido al relativismo $y$, en definitiva, la irracionalidad que tal postura implica. Kenny ${ }^{44}$ ha afirmado que la evidencia y las razones no son irrelevantes para aceptar o rechazar una creencia como básica, y Levine ${ }^{45}$ que hace falta un criterio para discriminar la basicalidad de la basicalidad propia. Pero lo más dudoso es que la proposición kexiste Dios" pueda - y deba- contarse entre las creencias propiamente básicas de una persona.

Otro terna que empieza a suscitar el interés hacia los ochenta de la mano de John Hick es el del pluralismo religioso. Hick es probablemente el filósofó dé la religión más completo, y no hay tópico sobre el que no haya escrito con amplitud y profundidad. ${ }^{66}$ Pero de su mano, primero en el Princeton Theological Seminary y luego en la Claremont Graduate School, se han forjado importantes especialistas en religiones - sobre todo orientales-. Su reciente $A n$ Interpretation of Religion, es una muestra de cómo una filosofía de la religión a la altura de los tiempos debe tener en cuenta, no sólo todos los avances de la filosofía de la religión (Philosophical Theology inclusive), e incluso de las ciencias de la religión, sino un conocimiento profundo de las diversas religiones y su historia. Él pretende que todas las grandes religiones tienen por referente lo Real en sí, algo inaccesible y más allá de todo pensamiento y lenguaje (noúmeno), de lo cual cada religión 
capta algunos aspectos (fenómenos), que expresa en forma mitológica y simbólica. En este sentido, todas las grandes religiones son verdaderas en cuanto que todas contactan con lo Real y son medios de salvación/liberación, pero todas son falsas al pretender absolutizar su representación -meramente fenoménica- de lo Real y al tomar como verdades literales mitos inveterados (ser el pueblo elegido - judios-, o la encarnación de Dios - cristianos-). Difícil y problemático, como es sin duda el intento, probablemente es la única filosofía de la religión posible en un futuro.

Ha habido otros muchos temas que no han sufrido un "revival" en un período determinado ni han constiluido una tendencia de investigación defini$\mathrm{da}_{\text {, }}$ pero que nunca han dejado de estudiarse en nuestro ámbito: la experiencia religiosa, la inmortalidad y la vida ultraterrena, los milagros, y un largo etcétera. Pero no nos queda ya espacio para ellos. Terminamos refiriéndonos al estado actual y a la situación en España.

Actualmente destacan las siguientes características. Primero, la filosofía analítica de la religión, como la de la ciencia o la del lenguaje, ha devenido una escolástica más, con las ventajas e inconvenientes que ello comporta: una ingente cantidad de publicaciones, simposios, sociedades, revistas; pero una frecuente repetición (algunos autores publican media docena de veces el mismo artículo con mínimos retoques) acompañada de una proporcional dísminución de la calidad; una comunidad de discusión (paradigma) coherente y cohesionada, pero totalmente impermeable a (cuando no despreciativa de) todo lo que no se escriba en inglés. Segundo, un amplio dominio de las técnicas filosóficas típicas del ámbito (lógica modal, lógica filosófica, análisis lingüístico-conceptual, epistemología, filosofia de la ciencia...) que permiten ri$\cos \mathrm{y}$ sugerentes enfoques nuevos al aplicarlas a los temas religiosos; pero un desconocimiento bastante generalizado (con excepciones como John Hick o Ninian Smart) de las ciencias, la fenomenología, o la misma historia de las religiones. ${ }^{47}$ Tercero, un desplazamiento geográfico de Gran Bretaña a los EEUU -paralelo a un curioso aumento de los filósofos creyentes sobre los no creyentes, hoy en franca minoría-. Y cuarto, un renovado interés por los temas más metafísicos y teológicos (algunos típicamente medievales) con el consiguiente interés por toda la gran tradición filosófica hasta el siglo XVIII. $^{48}$ Particularmente ahora mismo hay un gran auge de la teología dogmática cristiana hecha a partir de las teorías filosóficas más recientes; ${ }^{49}$ los lógicos y filósofos más sutiles ¡se ocupan de la Trinidad o la Encamación! En esta labor tiene especial mérito la Society of Christian Philosophy, fundada en EEUU en 1978, y su prestigiosa revista Faith and Philosophy, a partir de 1984; y, muy especialmente, la universidad católica de Notre Dame (Indiana).

La situación en España es bien distinta. La filosofía de la religión no es una materia muy relevante en nuestro país, y la analítica ha pasado casi completamente desapercibida. El primer trabajo que conozco es el importante artículo de Javier Mugerza «El problema de Dios en la filosofía analítica", 50 quien nos presentó rigurosa y críticamente la disciplina de marras, para luego, desgraciadamente, abandonarla. A ella siguieron los libros de Javier Sádaba lenguaje religioso y filosofía analítica (una cxposición clara, profunda y bien documentada de los principales tópicos), Qué es un sistema de creencias (una obra menor donde se repasan las 
idcas de Flew, Findlay, Hanson, Winch y otros), y la colección de artículos $F i$ losofia, lógica, religión (algunos meramente exponen a nivel más elemental lo tratado en el primer libro, otros se concentran sobre un tema muy concreto, siempre con abundante información de primera mano). En su más reciente Lecciones de filosofía de la religión ${ }^{51}$ deja de exponer las ideas de los analíticos para presentar su propia postura -y su prospectiva de la filosofia de la religión en nuestro país-, una postura que él califica de "religiosa" y que se identifica con el Wittgenstein más agnóstico. Es un libro, empero, más de divulgación que los anteriores.

Además de esto he encontrado referencias ocasionales a la filosofía analítica de la religión en las excelentes Metafísica trascendental y Filosofia de ia religión, de José Gómez Caffarena. ${ }^{52}$ También tiene en cuenta a la tradición analítica Carlos Díaz en su reciente y exhaustivo Preguntarse por Dios es razonable. Ensayo de teodicea, ${ }^{53}$ particularmente en lo referente al tema del len- guaje y al argumento ontológico. Por último hay que destacar La coincidencia de los opuestos en Dios, ${ }^{54}$ de Lorenzo Peña. Se trata de una obra amplia y densa, magnificamente documentada, donde se tocan casi todos los tópicos de la teología filosófica en la línea de la mejor filosofía analítica, sin olvidar las aportaciones de la gran tradición continental. Es una obra, lamentablemente poco difundida, en la que el autor toma siempre postura, generalmente de modo original y llegando a menudo a tesis discutibles, pero siempre con fundamentación. Quizá la terminología inventada que emplea dificulte innecesariamente una obra ya de por si «enjundiosa».

En lo tocante a las traducciones, tampoco son numerosas, si bien, algunas valen la pena. ${ }^{55}$ Por nuestra parte sólo nos queda expresar el desideratum de que la recién nacida Isegoría y el Instituto de Filosofía sean, como ya han empezado a serlo, activos difusores y, ¿tpor qué no?, creadores de filosofía de la religión en España, incluida la analítica.
1. Claro que, aparte de Hume, cuyas obras son constantemente citadas en nuestro circulo, hay una larga tradición de filosofía de la religión cuyos jalones principales son la Natural Theotogy de Paley (1802), A Grammar of Assent de Newmann (1870), las Varieties of Religious Experience de James (1902) (hay trad. esp. en Barcelona, Peninsu1a, 1986), y la Philosophical Theology de Tennant (1928). Para el último siglo de esta historia cf. A.P.F. Shell: The Philosophy of Retigion: 1875-1980, Londres, Croom IIelm, 1988.

2. "Comientes principales en filosofía analitica de la religiono, Antrario del Departamento de Filosofta, Universidad Autónoma (Madrid), V (198889), pp. 253-279. A el rernitimos al lector para una exposición más detallada de lo que aquí solo podemos esbozar.

3. En realidad se trata de una colección de arm tículos publicados en varias épocas compilados en
1956. El artículo principal que da título al Jibro data de 1927. Hay trad. en Edhasa, Barcelona, 1983 y reed.

4. Aunque algunas de sus partes son anteriores. Por ejemplo, el desafio de Flew se publico en la revista Untiversity en 1951. La obra fue publicada en Londres por SCM Press, con sucesivas reediciones.

5. Este debate ha sido clara y ajustadamente narrado por Dario Antiseri en El problema del tenguaje religioso, Madrid Cristiandad, 1976 (ed. original, 1969). Más recientes son recomendables: Jeffner, A.: The Study of Religious Language, Londres, SCM Press, 1974, y Soskice, J.M.: Metaphor and Religious Language, Oxford, Clarendon, 1985.

6. El más prolffico. Es importante su Religious Language, Londres, SCM Press, 1957.

7. Editada por Basil Mitchell en Londres, Allen \& Unwinn, 1958. Aqui destaca The Possibility of Theological Statements», de Ian Crombie. 
8. Se trata de Faith ond the Prilosophers, editada por John Hick, Londres, Macmillan, 1964.

9. Antologías muy completas son: Santoni, E.R. (ed.): Religious Language and the Problem of Reltgious Knowledge, Bloornington, Indiana U.P., 1968; y Cahn, S.M. S Shatz, D. (eds.): Contemporary philosophy of Religion, Nueva York, Oxford U.P. 1982. Más pequeña pero muy bien escogida es la de Basil Mitchel (ed.): The Philosophy of Religion, Oxford, Oxford U.P., 1971. Buenas introducciones son: Hick, John H.; Philosophy of Religion, Nueva York, Englewood, 1963; Flew, A.: Cod and Philosophy, Londres, Hutchinson, 1966 (hay trad. esp. en El Ateneo, Buenos Aires, 1976); Davies, B.: An Introduction to the Philosophy of Religion, $\mathrm{Ox}$ ford, Oxford U.P. 1982, y Evans, C.S.: Philosophy of Religion. Thinking about Faith, Dovners Grove (ILL), IVP, 1985.

10. Ithaca (NY), Cormell U.P., 1967.

11. Oxford, Clarendon Press, 1974.

12. Respectivamente, "Can God's Existence Be Disproved?", Mind (1948) -y luego en la antología de Flew y Macintyre-; y "Is Necessary Existence Possible?", Philosophy and Phen. Research, 15 (1955).

13. Charles Hartshome lo vio primero en Man's Vistor of God, Nueva York, Harper \& Row, 1949, y luego en Anselm's Discovery. La Salle (ILL). Open Court, 1965. El célebre articulo de Norman Malcolm es "Anselm's Ontological Arguments", The Philosophical Review, LXIX (1960), ahora en las provechosas antologias sobre el argumento ontologico: Hick, J.H. McGuill, A. (eds.): The Many-Faced Argument, Londres, Macrnillan, 1968 y Plantinga, A. (ed.): The Ontological Argument (idem).

14. La bibliogralía es enome, La trayectoria del problema hasta la actualidad puede seguirse con detalle en nuestro "El argumento ontológico en la "Philosophical Theology"s, que aparecerá en la obra colectiva patrocinada por el Instituto de Filosofia Materiales para una flosofia de la religion. Entre las criticas recientes al argumento destacan: Kane, R.H.: *The Modal Ontological Argument", Mind, 93, 1984, y Paulsen, D.: "The Logically Possible, the Ontologically Possible and Ontological Proofs of God's Existencen, Intemational Journol for the Philosophy of Religion (en adelante IJPhR), 16 (1984). Entre los defensores destaca el prolífico discipulo de Plantinga, Thomas Morris. Cf. su "Necessary Beings", Mind, 94 (1985), ahora en su Anselm's Explorations, Notre Dame U.P., 1987.

15. Mind, 64, 1955. La misma idea, sin llegar a afirmar la incoherencia del tersmo, aparece en A. Flew \&Divine Omnipotence and Human Freedom*, en su antología de 1955.

16. Primero on *The Free Will Defence* en $M$. Black (ed.), Philosophy in America, Londres, Allen
\& Unwinn, 1965. Luego en el cap. 9 de su The Nature of Necessity.

17. Este es el título -en ingles- de su artículo en Philosophical Studies, 35 (1979).

18. Londres, Macmillan.

19. Para esta historia cf. el excelente «Recent Work on the Problem of Evil de M.L. Peterson, American Phitosophical Quarteriy, 20 (1983), pp. $321-339$.

20. Y también de las Obsenvaciones a la «Rama Dorada" y las Obsenvaciones filosoficas.

21. Recogidas en Stuart C. Brown (ed).: Reason and Religion, thaca (NY), Comell U.P. 1977. Son básicos los artículos s.Meaning and Religious Language de P. Winch, $y$ "The Groundlessness of Belief , así como las réplicas -..en nuestra opinión muy justas- de Brown, Durrant y Lyas.

22. Oxford, Blackwell, 1967. Uno de cuyos artfculos más clásicos es el de Perter Wirkh *Understanding a Primitive Societym. Las primeras obras de Phillips y Maloolm sobre el asunto se remontan a la mitad de los sesenta: Fhillips, D.Z.: The Concept of Prayer, Londres, Routledge \& K.P. 1965, y Malcolm, N.: "Is It a Religious Belief that "God Exists"?", en Hick, Fath and the Philosophers, cit. Para una bibliografía más amplia de los wittgensteinianos cf. el libro de J. Sádaba de 1977 citado al final del articulo (pp. 77-79). Lo más reciente de Phillips es Belief, Change and Foms of Life, Londres, Macmillan, 1986, y Faith after Foundationalism, Londres, Routledge \& K.P., 1988. De Winch. su colección de ensayos Tying to Make Sense, Oxford, Blackwell, 1987.

23. De entre las muchas, aparte las referidas, destacan *Wittgensteinian Fideism*, de Kai Nielsen, Philosophy, 42, 1967, quien ha vuelto a insistir varias veces hasta su An Introduction to the Philosophy of Religion, Londres, Macrillan, 1982.

24. Su obra es copiosa. Lo más significativo: Taking Leave of God, Londres, S.C.M. Press, 1980 y Oniy Human (idem, 1985).

25. "God and Human Attitudes", Refigious Stsdies, pp. 325-337. Ahora en Paul Helm (ed.): Divine Commands and Morality, Oxford U.P., 1981.

26. «Religious Obedience and Moral Autonomy", Religions Studies, 1975, pp. 265-282. Ahora en la mencionada antología de Paul Helm.

27. Divine Commands and Moral Requirements, Oxford, Clarendon, 1978.

28. Iohn H. Chandler: "Is the Divine Command Theory Defensible? , Religious Studies, 1984, pp. 443-452.

29. «Moral Obligation, Religious Demand and Practical Conflictn, en Robert Audi, (ed.): Rationatity, Religious Belief \& Moral Commiment, Ithaca (NY), Cornell U.P., 1986, pp. 195-212.

30. Nelson Fike: “Omnipotence and God's Ability to $\operatorname{Sin} *$. Richard Swinburne: Duty and the Will of God\%. Robert M. Adams: aA Modified Divi- 
ne Command Theory of Ethical Wrongnessm y "Divine Commands Metaethics as Necessary a Posterioris (todos en la citada antologia de Helm).

31. Peter Geach sThe Moral Law and the Law of God», en su God and the Soul, Londres, Routledge \& KP., 1969. Geach es uno de los Jógicos, filósolos morales y de la religión más importantes, son tambien valiosos sus "Omnipotence". Philo sophy, 48 (1973), Providence and Evil, Cambridge U.P., 1977, y The Virtues (idem).

32. Por cjemplo: Jaseph Lombardi: "Worship and Moral Autonomy», Religious Studies, 1988, pp. 101-120. y C.L. Coulter: «Moral Autonomy and Divine Commands;, Religious Studies, 1989, pp. 117-130. Y tambiên Robert M. Adams: "Atonomy and Theological Ethics; en su The Virtue of Faith, Nueva York, Oxford L.P., 1987.

33. Actualizada en cuanto cuenta con nuevas herramientas - la logica modal, la lógica filosófica, la filosofia del lenguaje, la filosofia de la ciencia, la epistemología... y carece de presupuestos ajenos a la filosofía -empezando por la misma existencia de Dios y la verdad a prioti de la fe cristiana- Cosas ambas que no sucedian en el caso de nuestros egregios predecesores (de Agustín a Leibniz). Ast lo ve Anthony Kenny, al inicio de su The God of the Pritosophers -Oxford, 1979-, una lúcida revisión de los atributos tradicionalmente predicados de la divinidad.

34. Como ejemplo de cuestiones de las que se ocupa la filosofia de la religión pero no la teología filosófica: ¿tienen todas las religiones algo en común?, een qué medida son compatibles?, ¿comporta la religión necesariamente creencias?, ¿son la moral y la religión compatibles, o acaso es reducible una a otra?, ¿es el lenguaje religioso un ajuego de lenguaje distintivo?, etcetera.

35. Aparte de sus innumerables artículos, es ya clasica su trilogia The Coherence of Theism, The Existence of God, y Faith and Reason, todas en $\mathrm{Ox}-$ ford, Clarendon, 1977, 1979 y 1981 .

36. Para una ampliación de estos dos tópicos remitimos al Jector a nuestro \&Corrientes principales...n op. cit. pp. 272-279. Muy sugerentes los articulos recogidos en Freddoso, A.J. (ed.): The Existence and Nuture of God. Notre Dame U.P., 1983, y Morris, $\mathrm{T}$. (ed.): The Concept of God, Oxford, Oxford U.P., 1987. Sobre tópicos particulares: Wolterstorff, N.: "God Everlasting" (1975), ahora en la antología de Cahn citada; Pike, N.: God and Timelessness, Nueva York, Shocken, 1970; Helm, P.: "Timelessness and Foreknowledge". Mind, 85 , 1975, "Foreknowledge and Possibility", Canadian Jour. of Phil., 6. 1976, "Omunpotence and Change*, Philosophy, 51, 1970, y "God and Spacelessness $*$, jdem 55, 1980. Un clásico es la Phitosophicol Theology, Indianápolis, Bobs-Merrill, 1969, del lógico anselmiano-tomista John Ross. Más reciente es la ortodoxa defensa de la impasibilidad por
Richard Creel en Divine Impassibility, Cambridge U.P., 1985.

37. Además de las obras citadas de Flew y Niel. sen, son basicas: Kaufmann, W.: Critique of Religion and Philosophy, Princeton U.P., 1958 (hay trad. esp. Mexico, FCE, 1983); Flew, A.: The Prestumption of Atheism, Nueva York, Harper \& Row, 1976: Nielsen, Kai.: Contemporary Critiques of Reli. gion y Scepticism, Londres, Macmillan. 1971 y 1973; Mackie, J.: The Miracle of Theism, Oxford, Clarendon, 1982; y OTear, A.: Experience, Explanation and Faith. Londres, Routledge \& K.P., 1984. Todos son de gran altura, pero los argumentos se repiten mucho.

38. Según argumenta Basil Mitchell, las disputas filosoficas no se pueden dirimir como las cientificas apelando a demostraciones deductivas o a abrumadoras evidencías inductivas, sino más bien como en Derecho, acumulando argumentos pro y contra para emitir un veredicto - generalmente provisional y un tanto subjetivo-- Cf. su espléndido The Justification of Religious Belief, Londres, Macmillan, 1973.

39. Of. las pp. 116-151 de su The Existence of God Hemos ponderado los argumentos de una $y$ otra parte, destacando la relevancia de los recientes conocimientos en física $y$ astronomía para la cuestión, en nuestro «Argumento teleológico y cálculo de probabilidades", a aparecer en Pensamiento.

40. Los dos primeros en sus obras recien citadas, y Hick en su An Interpretation of Religion (cf. infra).

41. Editado por Plantinga y Wolterstorff (Notre Dame U.P., 1983), con aportaciones además de Alston, Mavrodes, Marsden y Holwerda. Este libro, en nuestra opinión suptavalotado, ha tenido enorme repercusión -en sólo una década más de cincuenta articulos-, si bien el artículo de Plantinga es muy superior al resto. A él le ban seguido otras obras colectivas, como la citada de Audi, o la de Runzo, J. \& Ihaza, C.K. (eds.): Religious Experience and Religious Belief, Lanham, Univ. Press of America, 1986.

42. "Christian Experience and Christian Belief" (en el colectivo de Plantinga y Wolterstorfn, "Plantinga's Epistemology of Religious Belief», en Tomberlin, J.E. \& Inwagen, P. van (eds.): Alvin Plantinga (Profiles), Dordrecht, Reidel, 1985, y "Religious Experience as a Ground of Religious Belief.", en el colectivo de Runzo recién citado.

43. "Reason and Belief in God", en Faith ard Rationality, p. 77. Plantinga ha escrito otros siete $\mathrm{u}$ ocho articulos sobre el tema.

44. Faith and Reason, Nucva York, Columbia U.P., 1983.

45. Hume and the Problen of Miracles: A Solution, Dordrecht, Reidel, 1989, p. 152 ss. Importantes criticas aparecen en Penelhurn, T: God aid 
Skepticism, Dordrecht, Reidel, 1983 y, desde dentro del tessmo, Gutting, G.: Religious Belief and Religious Skepticism, Notre Dame U.P., 1982; Quinn, P.: "In Search of the Foundations of Theism", Faith and Phitosophy, 2 (1985); Audi, $\mathrm{R}_{\text {: }}$ "Direct Justification, Evidential Dependence, and Theistic Belief», en la antología de la que es coeditor; $y$ Pojman, L.I.: Religious Betief and the Will, Lon. dres, Routledge \& K.P. 1989. Aparte de las obras de Swinburne (1982) y Phillips (1988).

46. De entre su vasta obra destacan Faith and Knowledge. Ithaca, Cornell U.P., 1957. Evil and the God of Love, Londres, Macmillan, 1966, Death and Eternal Life (idem), y An Interpretation of Religion, Londres, Macmillan, 1989, en donde ofrece una visión global de las religiones bajo todos sus aspectos. Especificamente sobre el pluralismo re ligioso son sus God and the Universe of Faiths, Nueva York. St. Martin, 1973 y Problems of Religious Plturatsm, Londres, Macrillan, 1985. Es asimismo editor o coeditor de muchas obras sobre el tema.

47. En la medida en que se pretenda hacer solo leologia filosofica (o Philosophy of Chistian Retigion, como a veces se denomina), esto no es un defecto. Pero si lo es para hacer filosofla de la religion, «uberhaupt».

48. Por contra, los autores no anglosajones de los siglos XIX y xx -salvo Kierkegaand y Wittgenstein-son olinmicamente ignotados.

49. Como mucstra, Morris, T.: The Logic of God Incamate. Ithaca, Cornell U.P., 1986 -donde se aplican la filosofía de la mente y la semantica sobre la identidad para resolver el problema de las "dos naturalezas" de Cristo-. Y los colectivos: Mortis, T. (ed.): Philosophy and the Christian Faith, Notre Danne U.P., 1988; Feenstra, R.J. \& Plantinga Jr., C. (eds.); Trinity, Incamation and
Atonement (idem 1989); y Flint, T. (ed.): Christian Philosophy, (ídem 1990).

50. Revista de Filosofta (Madrid). XXV (1966), pp. 291-366.

51. Publicados respectivamente en Barcelona, Ariel, 1977; Madrid, Mañana, 1978; Salamanca, Sigueme, 1978; y Madrid, Mondadori, 1989.

52. Madrid, Revista de Occidente, 1970 y 1973 ..el segundo, en colaboración con J. Martín Velasco-.

53. Madrid, Encuentro, 1989. Refiriéndose a la precariedad de nuestra corriente en España, afirma: "S6lo España ha llegado a ser tan "moderna" en filosofia, que no sabe nada de su presente por ignorar su pasado: ¿Por qué los ayer neopositivistas y analíticos a remolque no dan cuenta hoy, aunque sea de nuevo a remolque, de esta tradición operativa en la actualidad? (p. 343). Justa, pero unilateral, queja, a la que habria que añadir: cpor qué los filosófos de la religión españoles "pasan" alegremente de la filosofía analítica?

54. Ouito, Ediciones de la Universidad Católica, 1981 .

55. Además de las citadas a lo largo de las notas: Bochenski, J.M.: La lógica de la religion, Buenos Aires, Paidós, 1967; Macquarrie, J.: Godtalk. El anaitsis del lenguaje y la logica de la teologia, Salamanca. Sigueme, 1976; Varios: Filosofia de it ciencia y teligión, Salamanca, Sigueme, 1976; Albert, H.: La miseria de la teologia, Barcelona, Alfa, 1982; y Kolakowski, L.: Si Dios no existe, Madrid, Tecnos, 1985. Todos son valiosos aunque, curiosamente, ninguno es un "filósofó analítico de la religión*. Para tratar de rellenar esta laguna filosófica estamos traduciendo actualmente una docena larga de entre los artículos más representativos en nuestro campo.

\title{
Individuos e información: sobre el marxismo analítico
}

\author{
J. FRANCISCO ÁLVAREZ \\ UNED Madrid
}

Hace ocho años que Jon Elster desde las páginas de London Review of Books, en el artículo "Cien años de ciencia social marxista», recordaba un aforismo de Alfred North Whitehead: «Una ciencia que se resiste a dudar de sus fundadores y a olvidarlos está perdidan. ${ }^{1}$ Allí Elster señalaba sus particulares objeti- 